\title{
Adrenergic influences on coeliac ganglion affect the release of progesterone from cycling ovaries: characterisation of an in vitro system
}

\author{
Z Y Sosa, M Casais, A M Rastrilla and L Aguado \\ Laboratorio de Biología de la Reproducción (LABIR), Facultad de Química, Bioquímica y Farmacia, Universidad Nacional de San Luis, San Luis, Argentina \\ (Requests for offprints should be addressed to L I Aguado, Universidad Nacional de San Luis, Chacabuco 917, 5700, \\ San Luis, Argentina; Email: labir@unsl.edu.ar)
}

\begin{abstract}
The superior ovarian nerve (SON) arrives at the ovary through the suspensory ligament and innervates mainly the ovarian stroma. Most neurones from which the SON fibres originate are located in the complex coeliac and mesenteric ganglia. Taking into account that other ganglia have been shown to have $\alpha$ - and $\beta$-adrenergic receptors, and that the coeliac ganglion receives adrenergic fibres from other sympathetic paravertebral and preaortic ganglia, we utilised adrenergic agonists and antagonists specific to the ganglion, to analyse the role of the $\alpha$ and $\beta$ receptors in ovarian physiology. To that end, it was necessary to develop and standardise an in vitro coeliac ganglion-SON-ovary (coeliac ganglion-SON-O) experimental system that would enable study of the release of steroids in the ovary in the absence of humoral factors. We investigated the effect of adrenergic agents on the liberation of progesterone in the different stages of the oestrous cycle.To this end we placed the coeliac ganglion and the ovary in different compartments, connected through the SON, to produce a system being studied as a whole. Combined neural and hormonal (luteinising hormone (LH)) effects were also examined.

Non-specific stimulation with $\mathrm{KCl}$ in the ganglion compartment evoked different responses in terms of release of progesterone, depending on the physiological conditions of the cycle; this demonstrated the sensitivity and viability of the system.

During pro-oestrus, stimulation of the ganglion compartment with adrenergic agents such as the agonist noradrenaline or the $\beta$-adrenergic antagonist propranolol, did not modify the release of progesterone. In contrast, the $\alpha$-adrenergic antagonist, phentolamine, induced a strong inhibitory response. During the oestrous stage, noradrenaline was inactive, but phentolamine and propranolol exerted a strong stimulus throughout the experiment. On dioestrus
\end{abstract}

day 1 (D1), both noradrenaline and propranolol increased the release of ovarian progesterone, whereas phentolamine had the opposite effect. Finally, on dioestrus day 2 (D2), what was noteworthy was the pronounced inhibitory effect of noradrenaline, whereas phentolamine was inactive and propranolol showed its greatest stimulatory effect.

In order to compare the combined neural and endocrine effects on the ovarian release of progesterone, the experiment was carried out during stages D1 and D2, when the corpora lutea are at their peak of activity. Adrenergic agents were added to the ganglion and LH in a final concentration of $50 \mathrm{ng} / \mathrm{ml}$ was added to the ovarian comparment. Different effects were observed indicating a differential response to these agents in stimulated and basal conditions.

We conclude that the in vitro coeliac ganglion-SONovary system is a functional entity because it possesses its own autonomic tone. This is verified because different basal values of progesterone appear in the different stages of the oestrous cycle. In similar fashion, variations of progesterone induced via the neural pathway were observed under different experimental conditions. In contrast, on D2, noradrenaline added to the ganglion compartment had an inhibitory effect on the liberation of ovarian progesterone.This would indicate that, during this phase, noradrenaline may not be the neurotransmitter released in the ovarian compartment, but that other inhibitory molecules might participate in the observed effects. Finally, during D2, the neural input would condition the ovarian response to $\mathrm{LH}$, facilitating the decrease in progesterone necessary to start a new cycle.

The experimental scheme is, in our opinion, a valuable tool for the study of peripheral neural participation in ovarian physiology.

Journal of Endocrinology (2000) 166, 307-318

\section{Introduction}

In addition to the classic neuroendocrine system, in the past few years evidence has been found supporting a direct neural connection between the gonads and the central nervous system (Kawakami et al. 1972, 1981, Chiapas et al. 1977, De Bortoli et al. 1998). Innervation of the rat ovary is through two pathways. Of these, the superior ovarian 
nerve $(\mathrm{SON})$ is considered to be the main neural pathway related to ovarian steroidogenesis. This view is supported by the fact that the sympathetic nerve endings are in close contact with the stromal cells, especially with the thecal and interstitial cells (Jordan 1981, Aguado et al. 1982, Burden et al. 1985, Erikson et al. 1985). With regard to the origin of the SON, it is known that the neuronal soma of the fibres that constitute it are located in portions T10 and T11 of the medulla (Lawrence \& Burden 1980, Burden 1985). Most of the fibres that emerge from the medulla form synapses in the coeliac ganglion, thus integrating the fibres of the SON (Sarper et al. 1976, Lawrence \& Burden 1980, Sejnowski 1982, Chávez et al. 1991). The remaining fibres that come from the medulla do not form synapses at the ganglion, and arrive together at the ovary (Messenger et al. 1994). In addition, the connection between the ovary and the coeliac plexus through the SON has been confirmed, using retrograde axoplasmic transport (Baljet \& Drukker 1980, Klein \& Burden 1988a,b).

It is known that the ganglia involved in the SON pathway are sympathetic and their stimulation releases noradrenaline and other substances such as vasoactive intestinal peptide (VIP) (Ojeda \& Aguado 1985, Ojeda \& Lara 1989, Gerendai et al. 1995). It is important to point out that $\beta$-adrenergic receptors have been found in different populations of rat ovarian cells and in membranes of whole ovaries (Jordan 1981, Aguado et al. 1982, Condon \& Black 1976, Hsueh et al. 1984, Aguado \& Ojeda 1986, Norjavaara et al. 1989). The liberation of ovarian steroids, progesterone and aromatisable androgens is regulated by the number of $\beta$-adrenergic receptors (Aguado et al. 1982) and by the action of peptides with inhibitory effects such as those of gonadotropin-releasing hormone $(\mathrm{GnRH})$ (Hsueh \& Erickson 1979, Hsueh \& Jones 1981, Pieper et al. 1981, Sheela Rani et al. 1983) and GABA, the presence of which has been confirmed in ovarian tissue (Erdö et al. 1985), and with stimulatory effects such as that of VIP (Ahmed et al. 1986, Ojeda et al. 1989, Dissen et al. 1993, Kaleczyc et al. 1995).

The importance of the connection through the SON has been emphasised by experiments in which that neural pathway was partially or completely cut, for studies of the release of ovarian steroids in different in vitro systems (Aguado \& Ojeda 1984a, Marchetti et al. 1987). When central adrenergic stimulation is performed on cycling rats, the effect of this stimulation on the release of progesterone surpasses the corresponding effect of luteinizing hormone $(\mathrm{LH})$, which shows the greater influence of neural control on ovarian function in the adult rat (De Bortoli et al. 1998). Another experimental scheme utilised to evaluate neural participation in the control of ovarian function has been compensatory ovarian hypertrophy, which can be generated by unilateral ovariectomy (Burden 1978), or by chemical sympathectomy through the local action of 6-hydroxydopamine in the ovaries of rats in situ (Gerendai et al. 1978). Unilateral ovariectomy produces a decrease in the steroid hormones, provoking an alteration in the negative feedback mechanism, with a consequent increase in gonadotrophins that would produce an increase in the weight of the remaining ovary (Butcher 1977). Conversely, these neural pathways must remain intact for compensatory ovarian hypertrophy to occur. As a result, it has been proposed that a neuroendocrine mechanism could be responsible for the changes observed in compensatory ovarian hypertrophy (Burden \& Lawrence 1977, Gerendai et al. 1978). On the basis of these ideas, Chávez \& Domí nguez (1994) suggested that the incidence of compensatory ovarian hypertrophy attributable to neural information that reaches the ovary through the SON varies during the oestrous cycle. The mechanisms that produce these conditions are not fully understood, but it is possible that the peripheral nervous system functions as a nexus of rapid information about the endocrine status of the ovary and the central nervous system (CNS), or else that the ovarian hormones directly affect the activity of the CNS (Burden 1978).

In summary, the preceding details lead us to conclude that the sympathetic innervation of the ovary is necessary for the regulation of the function and the development of that organ, and for the rhythmic interaction of the ovary with the hypothalamo-hypophyseal axis during the oestrous cycle (Lara et al. 1990a,b). However, studies that use stimulation of the peripheral neural pathways are few (Gerendai et al. 1995). In addition to this, it is very difficult to determine if the effects are purely neural when in vivo schemes are used. These shortcomings led us to standardise a complete, integrated in vitro system that comprises the coeliac ganglion, the SON and the ovary, in this way avoiding the interference of humoral factors, especially the pituitary hormones. We also wanted to determine whether the occupation of the adrenergic receptors by the antagonists phentolamine and propranolol caused a response, such as the liberation of ovarian steroids. To this end, in the scheme we propose, the coeliac ganglion was stimulated with catecholamines and the release of progesterone from the ovary was studied. In addition, the existence of possible changes in the release of progesterone when LH is present in the ovary was evaluated. The experimental scheme is, in our opinion, a valuable tool for the study of peripheral neural participation in ovarian physiology.

\section{Materials and Methods}

\section{Animals}

Three-month-old female virgin rats (250-300 g), bred in our laboratory and originally of the Holtzman strain, were used in all experiments. The rats were kept under controlled conditions with lights on from 0700 to $1900 \mathrm{~h}$ and at a temperature of $24 \pm 2{ }^{\circ} \mathrm{C}$. Animals had free access to 
$A$

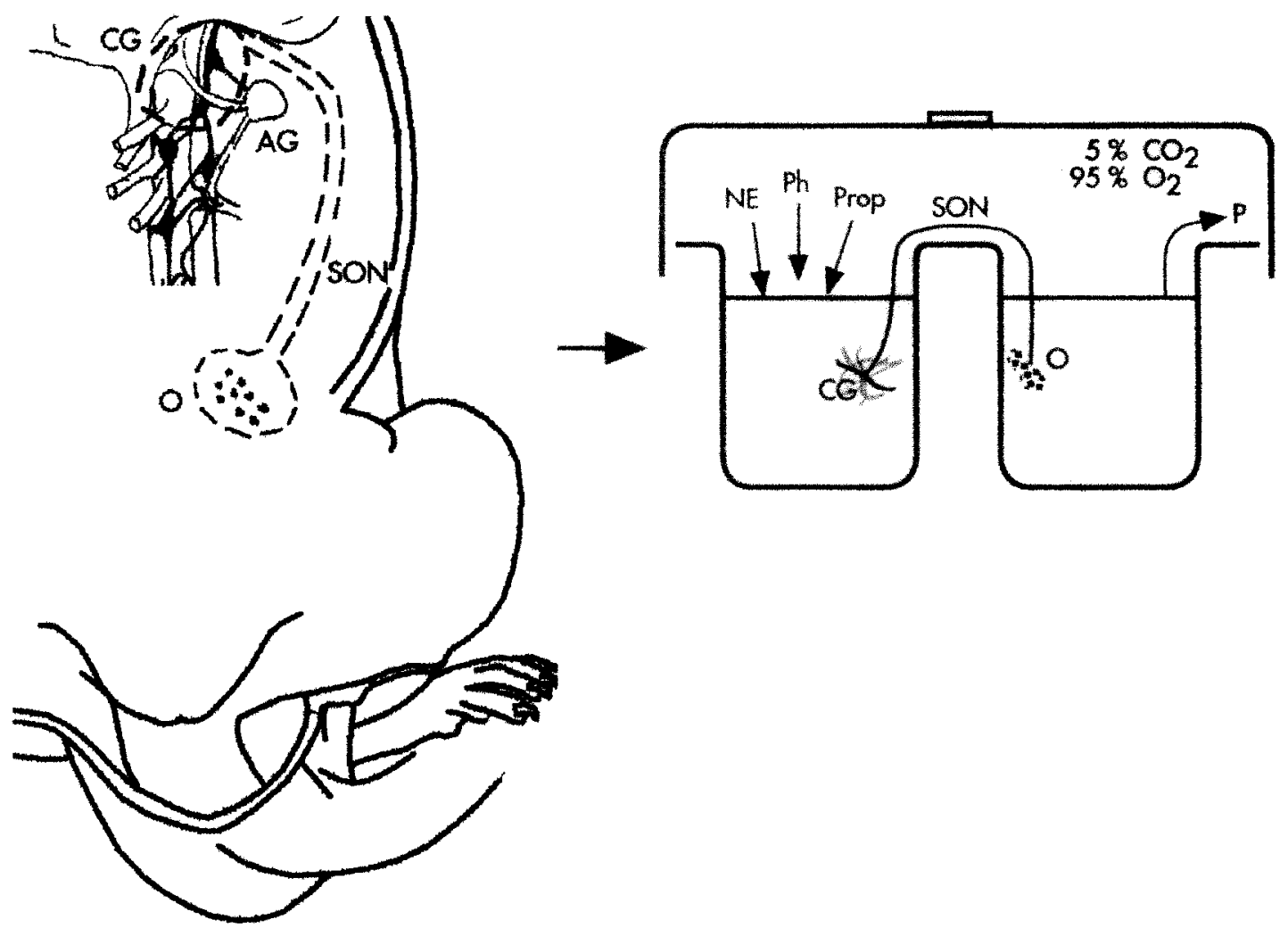

Figure 1 (A) Schematic representation of the SON pathway and the anatomical relationships of the nerve, ovary and coeliac ganglion. The dotted lines indicate sites where the coeliac ganglion-SON-ovaryO system was dissected out. (B) The cuvette utilised for the subsequent incubation of the system. AG, adrenal gland; CG, coeliac ganglion; NE, noradrenaline; $\mathrm{O}$, ovary; $\mathrm{P}$, progesterone; $\mathrm{Ph}$, phentolamine; Prop, propranolol.

food (Cargill SACI, Saladillo, Provincia de Buenos Aires, Argentina), and tap water was available ad libitum. Vaginal smears were taken daily and only those rats showing at least two consecutive 4-day oestrous cycles were used. Groups of six to eight animals in pro-oestrus, oestrus, dioestrus day 1 (D1) and dioestrus day 2 (D2) were used for the experimental procedure.

The experiments were performed in accordance with The Guidelines on the Handling and Training of Laboratory Animals, The Biological Council, UFAW 1992.

\section{Reagents}

The following drugs were purchased from Sigma Chemical Co. (St Louis, MO, USA): L-D-norepinephrine hydrochloride, L-propranolol hydrochloride, phentolamine hydrochloride, dextrose, ascorbic acid, bovine serum albumin fraction $\mathrm{V}$ (BSA), and LH. 1,2,6,7$\left[{ }^{3} \mathrm{H}\right]$ Progesterone was provided by New England Nuclear (Boston, MA, USA). Other reagents were of analytical grade.

\section{Surgical procedures}

A piece of tissue containing the left ovary, the fibres that constitute the SON, and the coeliac ganglion accompanied by some small ganglia that surround it, were removed (Fig. 1A); the adrenal gland and the small nerves contained in the peritoneum, oviducts, aortic tissue and the rest of the suspensory ligament were not removed. The strip of tissue was carefully dissected avoiding contact between the surgical instruments and the nerve fibres or the ganglion. This is essential in order to prevent spontaneous depolarisations of the nerves, which an inappropriate contact could provoke. The total surgical procedure was completed in 


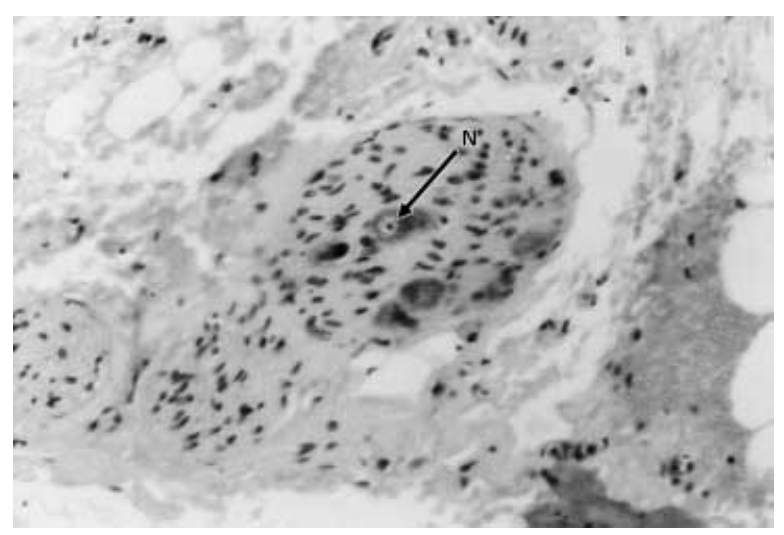

Figure 2 Survey photomicrograph of a coeliac ganglion, showing neural somas $(\mathrm{N})$ and fat connective tissue. Stained with haematoxylin-eosin. Original magnification, $\times 250$.

1-2 min. We proceded according to previous descriptions of the anatomical trajectory of this neural pathway Lawrence \& Burden 1980, Burden et al. 1982).

\section{Characterisation of the system and histological control}

The presence of the ganglion in the preparation used was confirmed by the application of routine histological techniques. Immediately after dissection, the material was fixed with Bouin's fluid. Serial cuts of $5 \mathrm{~mm}$ thickness were carried out utilising a sliding Reichert-Jung HN-40 microtome. Preparations were stained with haematoxylineosin and coated with sintetle balsam. The micrographic image was captured using a Leitz-Dialux photomicroscope, equipped with a Leica camera. This system, using a $25^{\prime}$ objective, was used to examine tissue sections (total magnification $\times 250)($ Fig. 2).

\section{Standardisation of incubation times}

The rats were anaesthetised with ether, described in Surgical Procedures and performed between 1500 and $1600 \mathrm{~h}$, taking advantage of the stable concentrations of progesterone that occur at that time of day. The coeliac ganglion-SON-ovary system was removed, cleaned with incubation medium and placed immediately in a cuvette with two compartments. Each compartment contained

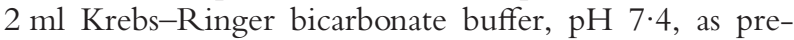
viously described, for in vitro culture of whole ovaries (Selstam et al. 1976, Advis \& Ojeda 1978, Advis et al. 1979, Aguado et al. 1982, Lara et al. 1990a,b, Ferruz et al. 1992). The ganglion was placed in one compartment and the ovary in the other, connected by the SON, which had to be kept moist with the experimental solution (Fig. 1B). The system was immediately put in a metabolic bath at $37^{\circ} \mathrm{C}$ in a $95 \% \mathrm{O}_{2}-5 \% \mathrm{CO}_{2}$ atmosphere, and the preincubation time necessary for its stabilisation was noted. A

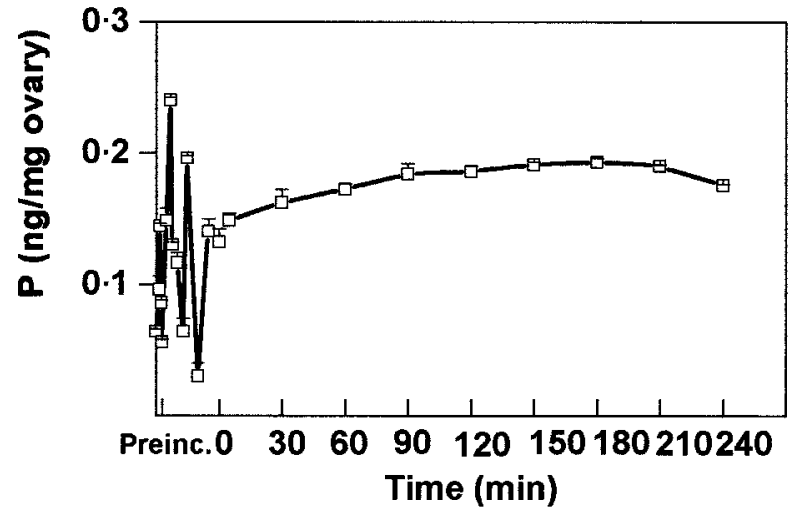

Figure 3 Incubation times. Release of progesterone $(\mathrm{P})$ by the ovary in the coeliac ganglion-SON-ovary system obtained from rats in D2. The system was incubated in Krebs-Ringer plus ascorbic acid solution at $37{ }^{\circ} \mathrm{C}$ in an atmosphere of $95 \% \mathrm{O}_{2}-5 \%$ $\mathrm{CO}_{2}$ for $240 \mathrm{~min}$. Progesterone concentrations were measured every 1 min for the first 5 min, then every 2 mins up to and including the 60th min, and thereafter every 5 mins up to and including the 240th min. Values are the means for three experiments \pm S.E.M. from six animals per experimental group.

previously standardised volume $(20 \mu \mathrm{l})$ of incubation medium was extracted from the ovarian compartment for the determination of progesterone every $1 \mathrm{~min}$ for the first $5 \mathrm{~min}$, then every $2 \mathrm{~min}$ up to and including the 60th min, and from then on every $5 \mathrm{~min}$ up to and including the 240th min. It was observed that stabilisation was achieved at $30 \mathrm{~min}$ (Fig. 3), which was then considered to be incubation time 0. At this time, the KrebsRinger solution was changed in both compartments and ascorbic acid $(0.1 \mathrm{mg} / \mathrm{ml}$ in Krebs-Ringer) was added as an antioxidant agent (Koh \& Hille 1997) in the ganglion compartment. The times of extraction of ovarian liquid were established at 30, 60, 120 and $180 \mathrm{~min}$.

\section{Experimental procedure}

Rats in pro-oestrus, oestrus, D1 and D2 were used. The values for the concentrations of progesterone released in the ovary compartment under the conditions described above were taken as basal (control group). The different substances to be tested were dissolved in equal concentrations $\left(10^{-6} \mathrm{M}\right)$ and volumes $(2 \mathrm{ml})$ of Krebs-Ringer solution plus ascorbic acid, and then added to the ganglion compartment for the measurement of progesterone release (experimental group). The adrenergic agents used in this investigation were noradrenaline as an adrenergic agonist, phentolamine as $\alpha$-antagonist and propranolol as $\beta$-antagonist. $\mathrm{KCl}(56 \mathrm{mM})$ was used as a non-specific depolarising stimulus (Koh \& Hille 1997). The samples of liquid from the ovarian compartment were maintained at $-20{ }^{\circ} \mathrm{C}$ until progesterone concentrations were to be determined by RIA. The results were expressed as nanograms progesterone per milligram ovarian tissue $(\mathrm{ng} / \mathrm{mg}$ 
tissue) against time of incubation. Appropriate corrections were made in all cases, taking into consideration the volume extracted in each period tested.

\section{Coeliac ganglion-SON-ovary system incubations with $\mathrm{LH}$}

In order to compare the simultaneous action of the neural effect and the endocrine effect on the release of ovarian progesterone, ovine $\mathrm{LH}$ was added $(50 \mathrm{ng} / \mathrm{ml}$ in incubation buffer) to the ovary compartment, and incubation medium with ascorbic acid to the ganglion compartment. The values for the liberation of progesterone thus obtained were considered basal (control LH group). Groups in which the liberation of progesterone without LH was determined were considered as controls.

The experimental groups were those that had added adrenergic agents - noradrenaline, phentolamine or propranolol - in the ganglion compartment, and ovine $\mathrm{LH}$ in the ovary compartment.

In accordance with the established schedule, incubation liquid was collected from the ovarian compartment of the control LH groups and from that of the experimental groups, and progesterone was determined by RIA. The results were expressed as progesterone $\mathrm{ng} / \mathrm{mg}$ tissue.

\section{Progesterone assay}

Progesterone was measured by RIA using antiserum raised against progesterone-11-BSA conjugate in rabbits, provided by Dr R Deis (Laboratorio de Reproducción y Lactancia, Mendoza, Argentina). The sensitivity, variability and crossreaction of this RIA have been reported previously (Telleria et al. 1994). The sensitivity of the assay is less than $5 \mathrm{ng} / \mathrm{ml}$ serum and the inter- and intraassay coefficients of variation were less than 10\%. This assay has been validated previously (Bussmann \& Deis 1979, Donoso 1988).

\section{Statistical analysis}

All data are presented as means \pm S.E.M. Statistical evaluations of the results were done with unpaired Student's $t$ test to assay significant differences between the means of the two groups. A value of $P<0 \cdot 05$ was considered statistically significant (Snedecor \& Cochran 1976).

\section{Results}

\section{Histological control}

The morphological study confirmed the presence of the coeliac ganglion in the isolated in vitro system. The ganglion was extracted from the area proximal to the coeliac artery and from the area proximal to the renal artery. Its elongated shape can be seen in the microphotograph (Fig. 2). It presents neural somas and is covered by a substantial amount of fatty connective tissue. This tissue probably provides additional protection against trauma, in addition to its other support functions (final magnification $\times 250$ ). During the standardisation of the system, we confirmed the existence of the ganglion in the preparation by means of histological studies. Afterward, we determined its spatial position in the rat for the purpose of subsequent extractions. We also analysed, immediately after incubation, preparations with vital colouration, for the purpose of proving the existence and viability of the ganglia.

Coeliac ganglion-SON-ovary system: effect of the addition of $\mathrm{KCl}$ to the ganglion compartment on progesterone release by the ovary in the oestrous cycle

In order to determine if stimulation of the ganglion affected the release of progesterone in the oestrous cycle, $\mathrm{KCl} 56 \mathrm{mM}$, considered to be a non-specific stimulating agent on the preganglionic nerve fibres, was added. In this case, the effect observed during pro-oestrus significantly decreased the release of progesterone at 30, 60 and $120 \mathrm{~min}(0.066 \pm 0.01$ compared with $0.036 \pm 0.001$, $P<0.05 ; \quad 0.072 \pm 0.01$ compared with $0.046 \pm 0.002$, $P<0 \cdot 001 ; 0 \cdot 084 \pm 0 \cdot 01$ compared with $0.062 \pm 0 \cdot 002$, $P<0.05$ ) respectively (Fig. 4, PE). However, in oestrus it caused a stimulatory effect on the release of progesterone at all times studied $(P<0 \cdot 001$; Fig. 4, E). During D1, the release of progesterone increased significantly in comparison with the controls at all times studied $(P<0 \cdot 001$; Fig. 4, D1) The pattern of liberation of progesterone in D2 rats shows that $\mathrm{KCl} 56 \mathrm{mM}$ caused a significant increase at $60 \mathrm{~min}(0 \cdot 218 \pm 0 \cdot 01$ compared with $0 \cdot 14 \pm 0 \cdot 01$, $P<0 \cdot 001)$, returning to values less than basal at $120 \mathrm{~min}$ and $180 \mathrm{~min}(0 \cdot 132 \pm 0 \cdot 01$ compared with $0 \cdot 17 \pm 0 \cdot 01$, $P<0.05 ; 0.130 \pm 0.008$ compared with $0.206 \pm 0.01$, $P<0 \cdot 001$; Fig. 4, D2).

Effect of the addition of adrenergic agents to the ganglion compartment on ovarian release of progesterone during the oestrous cycle

The presence of adrenergic agonists and antagonists in the ganglion compartment modified the release of ovarian progesterone at most times studied, depending on the stage of the oestrous cycle and the nature of the studied agent. For instance, in pro-oestrus, noradrenaline caused a significant increase in the release of ovarian progesterone only at $60 \mathrm{~min}(0.118 \pm 0.01$ compared with $0.072 \pm 0.01$, $P<0 \cdot 001)$, and when the $\alpha-$ adrenergic antagonist phentolamine was added to the ganglion compartment, it led to a considerable decrease (two- to threefold), in progesterone released at all times studied $(P<0 \cdot 001)$. However, when the $\beta$-adrenergic antagonist propranolol was added, no significant modifications were seen 

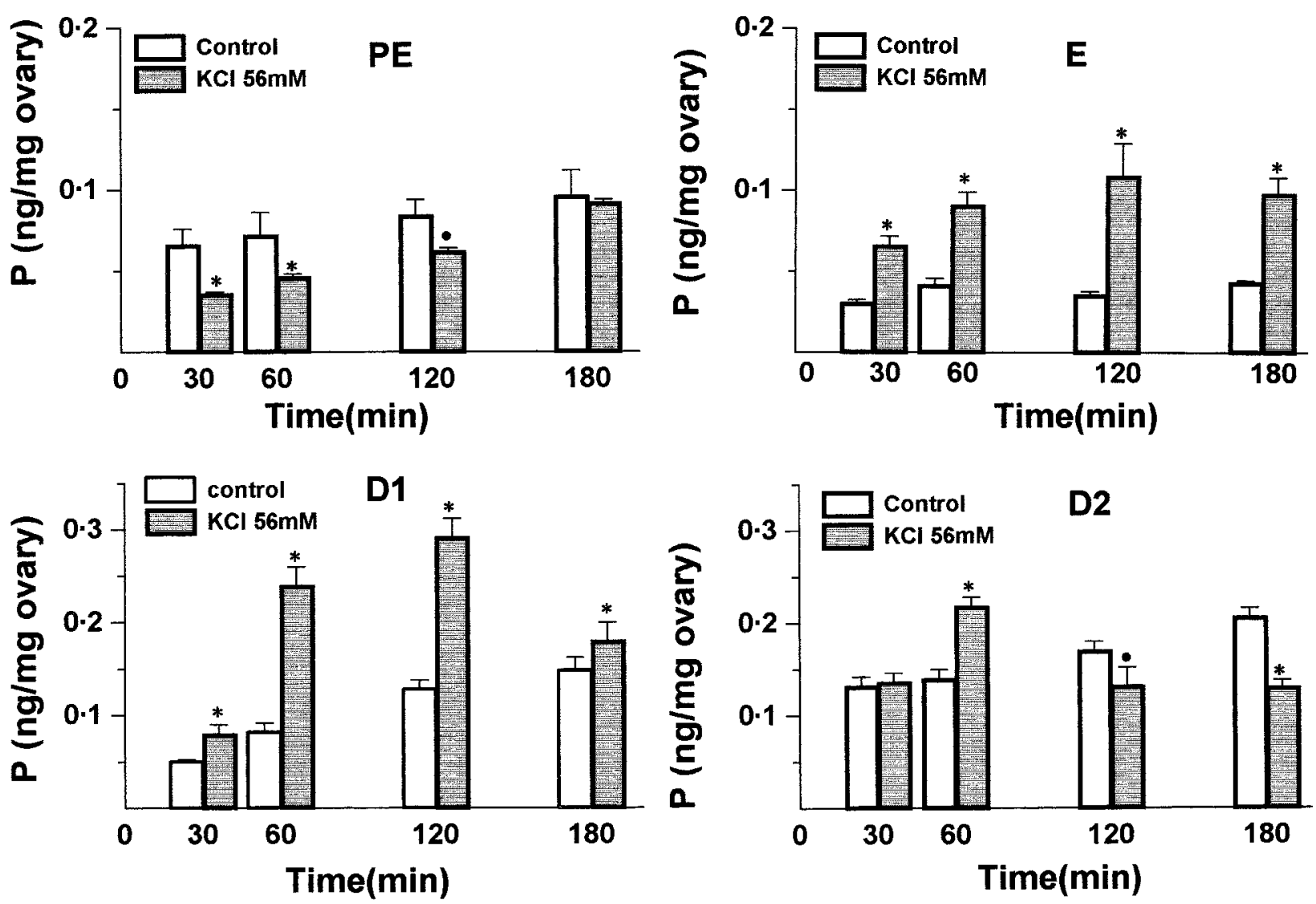

Figure 4 Effect of $\mathrm{KCl}(56 \mathrm{mM})$ in ganglion on release of progesterone by the ovary in the coeliac ganglion-SON-ovary system, obtained from rats in pro-oestrus (PE), oestrus (E), D1 and D2. The systems were incubated in the ganglion compartment in presence or absence of $\mathrm{KCl}$ in Krebs-Ringer plus ascorbic acid solution at $37^{\circ} \mathrm{C}$ in an atmosphere of $95 \% \mathrm{O}_{2}-5 \% \mathrm{CO}_{2}$ for 180 min. Values are the means \pm S.E.M. from six to eight animals per experimental group. ${ }^{*} P<0 \cdot 001$ and ${ }^{\bullet} P<0.05$ compared with respective control groups (Student's $t$ test).

compared with the controls, for all the times studied (Fig. 5, PE). During oestrus, noradrenaline induced a significant increase in the release of progesterone compared with the controls only at $30 \mathrm{~min}(0 \cdot 095 \pm 0 \cdot 001$ compared with $0 \cdot 031 \pm 0 \cdot 002, \quad P<0 \cdot 001)$, whereas phentolamine and propranolol induced a very significant increase in comparison with the controls at all times studied $(P<0 \cdot 001$; Fig. 5, E). When animals in D1 were examined, noradrenaline caused a significant increase (from two- to threefold) in the release of ovarian progesterone at all times studied $(P<0 \cdot 001)$, phentolamine decreased the release of progesterone with respect to controls $(P<0 \cdot 001)$, and propranolol induced a significant increase at all times analysed $(P<0 \cdot 05$; Fig. $5, D 1)$. During D2, an inhibitory response was observed with noradrenaline at all times $(P<0 \cdot 001)$ and with phentolamine there were no significant changes; with propranolol there was a very significant increase in the release of progesterone from the ovary at all times studied $(P<0 \cdot 001$; Fig. 5, D2).
Effect of LH during D1 and D2 in the ovary, with and without adrenergic agonist and antagonist stimulation in the ganglion

As the presence of $\mathrm{LH}$ is essential to the processes of ovulation and the luteinisation, its effect was evaluated during two stages in which corpora lutea were present and it was determined to have the main responsibility for the release of progesterone (Hsueh et al. 1984).

Without the presence of the stimulus in the ganglion, when LH was added to the ovary compartment a noticeable increase in the release of progesterone was observed, more prominent during D2 than D1 $(P<0 \cdot 001)$ compared with the respective control groups (Fig. 6, D1 and D2). The presence of noradrenaline in the ganglion compartment caused a considerable increase (two- to threefold) in the release of progesterone in D1 compared with the control LH $(P<0 \cdot 001)$. In contrast, phentolamine showed an inhibitory effect only at 30 and $60 \mathrm{~min}(0 \cdot 124 \pm$ 0.004 compared with $0 \cdot 081 \pm 0 \cdot 001$, and $0 \cdot 152 \pm 0 \cdot 008$ 

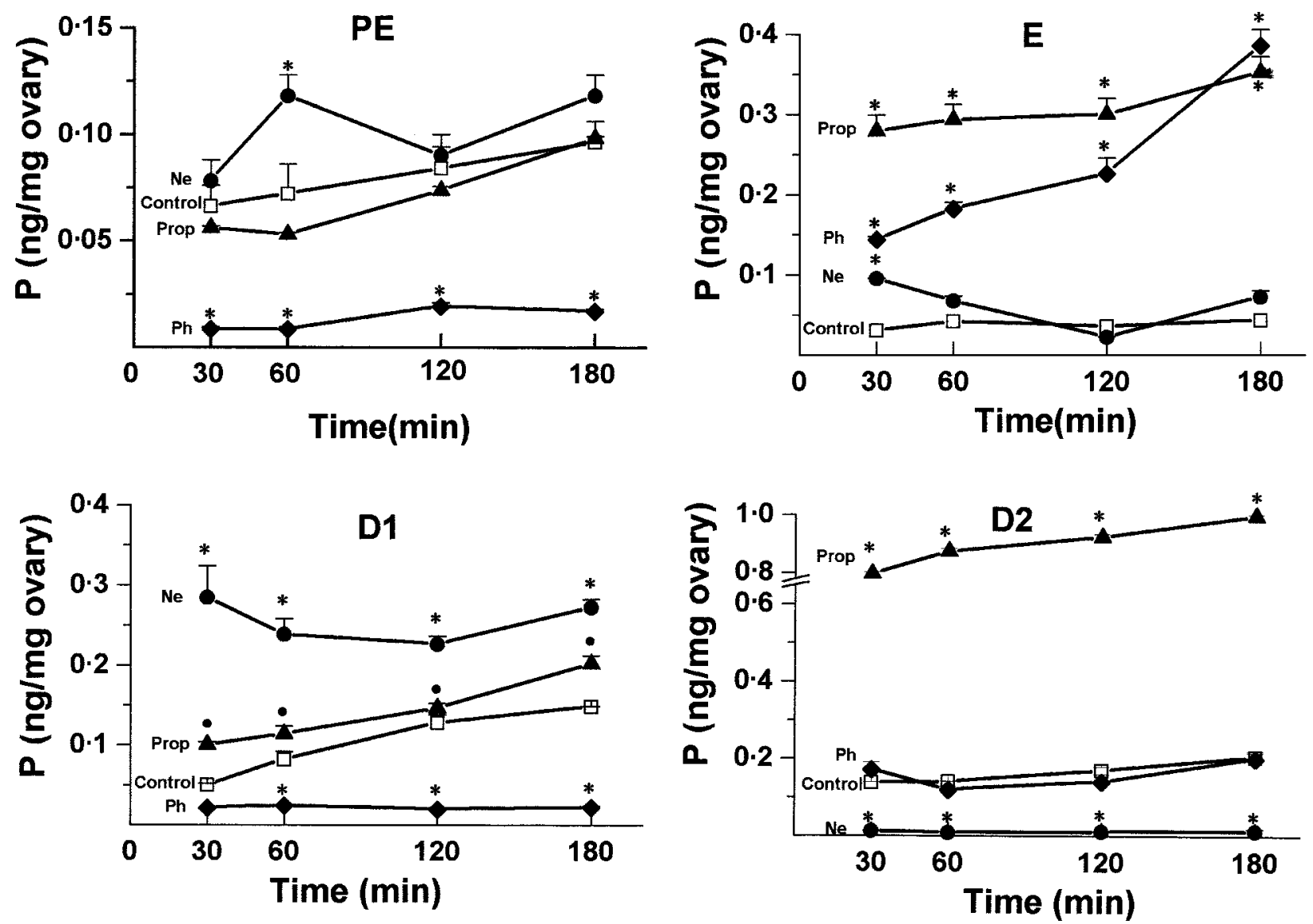

Figure 5 Effect of agonist and antagonist adrenergic agent in ganglion on ovarian release of progesterone (P) in the coeliac ganglion$\mathrm{SON}$-ovary system obtained from rats in pro-oestrus (PE), oestrus (E), D1 and D2. The systems were incubated in the presence or absence of agonist and antagonist adrenergic agents at $10^{-6} \mathrm{M}$ in Krebs-Ringer ascorbic acid solution at $37^{\circ} \mathrm{C}$ in an atmosphere of $95 \%$ $\mathrm{O}_{2}-5 \% \mathrm{CO}_{2}$ for $180 \mathrm{~min}$. Values are the means \pm S.E.M. from six to eight animals per experimental group. Ne, noradrenaline; Prop, propranolol; Ph, phentolamine. ${ }^{*} P<0.001$ and ${ }^{\bullet} P<0.05$ compared with the respective control groups (Student's $t$ test).

compared with $0 \cdot 104 \pm 0 \cdot 008, P<0 \cdot 05)$ compared with its control LH, whereas propranolol caused a significant decrease in the release of progesterone at all times studied $(P<0 \cdot 001$; Fig. 7, D1).

During D2, the presence of noradrenaline was associated with a diminution of the release of progesterone at 60 and $120 \mathrm{~min}(0 \cdot 400 \pm 0 \cdot 04$ compared with $0 \cdot 280 \pm 0 \cdot 02$, $P<0.001 ; \quad 0.420 \pm 0.02$ compared with $0.260 \pm 0.02$, $P<0 \cdot 01)$ compared with its control LH. The addition of phentolamine and propranolol decreased the release of progesterone even more (two- to threefold) at all times compared with its control-LH $(P<0 \cdot 001$; Fig. 7, D2).

\section{Discussion}

Several authors have provided evidence of a functional neural connection among different hypothalamic centres and the ovary, which contributes to its endocrine regu- lation (Kawakami et al. 1972, 1979, 1981, Weiss et al. 1982, Seto et al. 1988, Saito et al. 1990, Gerendai et al. 1995). However, at present there is not much information on the peripheral neural control during the different ovarian physiological states of the oestrous cycle, and consequently little is known about such control during two very important stages, D1 and D2, when the corpora lutea have great importance for the secretion of progesterone (Weiss et al. 1982). In vitro experiments involving incubating the ovary in the presence of adrenergic agonists show that, in the rat, the $\beta$ agonist induces the release of progesterone during the first oestrous cycle, including D2 after puberty (Aguado et al. 1982, Aguado \& Ojeda 1984a,b). In addition, it has been observed that both electrical stimulation and the dissection of the SON cause modification of both follicular development and ovarian steroidogenesis (Aguado \& Ojeda 1984a,b, Chávez et al. 1991, Chavez \& Domínguez 1994). This led us to study the physiological role of the entire peripheral nervous pathway (from the 

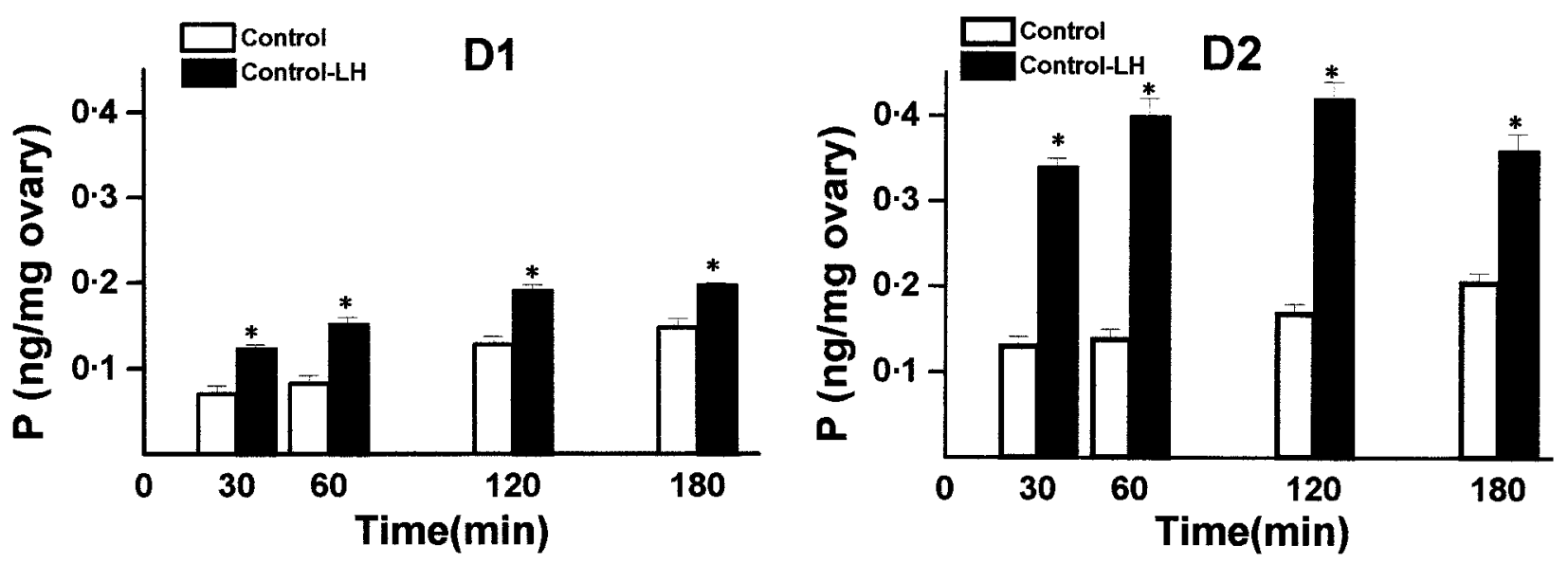

Figure 6 Progesterone $(\mathrm{P})$ release by the ovary in a coeliac ganglion-SON-ovary system obtained from rats in D1 and D2 with or without $\mathrm{LH}(50 \mathrm{ng} / \mathrm{ml})$ in the ovarian compartment. The systems were incubated in the ovarian compartment in the presence or absence of $\mathrm{LH}$ in Krebs-Ringer at $37{ }^{\circ} \mathrm{C}$ in an atmosphere of $95 \% \mathrm{O}_{2}-5 \% \mathrm{CO}_{2}$ for $180 \mathrm{~min}$. Values are the means \pm S.E.M. from six to eight animals per experimental group. ${ }^{*} P<0 \cdot 001$ compared with the respective control groups. (Student's $t$ test).

coeliac plexus through the SON to the ovary), not only under the control of the corpora lutea, but also under regulation by steroid secretion during all phases of the oestrous cycle.

For this purpose we sought an experimental design that could simulate in vitro the conditions that exist in vivo, preserving in particular the paracrine and autocrine mechanisms of regulation that take place in the ovary, and without humoral influence. For this, an integrated coeliac ganglion-SON-ovary system was designed and standardised, in which adrenergic stimulation took place in the ganglion, and neither ovarian structures nor innervation were affected. The presence of the ganglion was confirmed by histological studies moments before its surgical removal from the animal, and after the incubations. It did not present significant modifications with regard to in vivo conditions.

We assume that we have a system that is a functional entity, with its own autonomic tone, the latter point having been verified because the liberation of basal progesterone increases or decreases during the different stages of the oestrous cycle. We wanted to see if the occupation of the adrenergic receptors by the antagonists phentolamine and propranolol caused a response such as liberation of ovarian steroids. If this were not so, liberation of only basal progesterone would be stimulated in the presence of noradrenaline in the ganglion; however, the basal value was independent of the addition of the neuro-
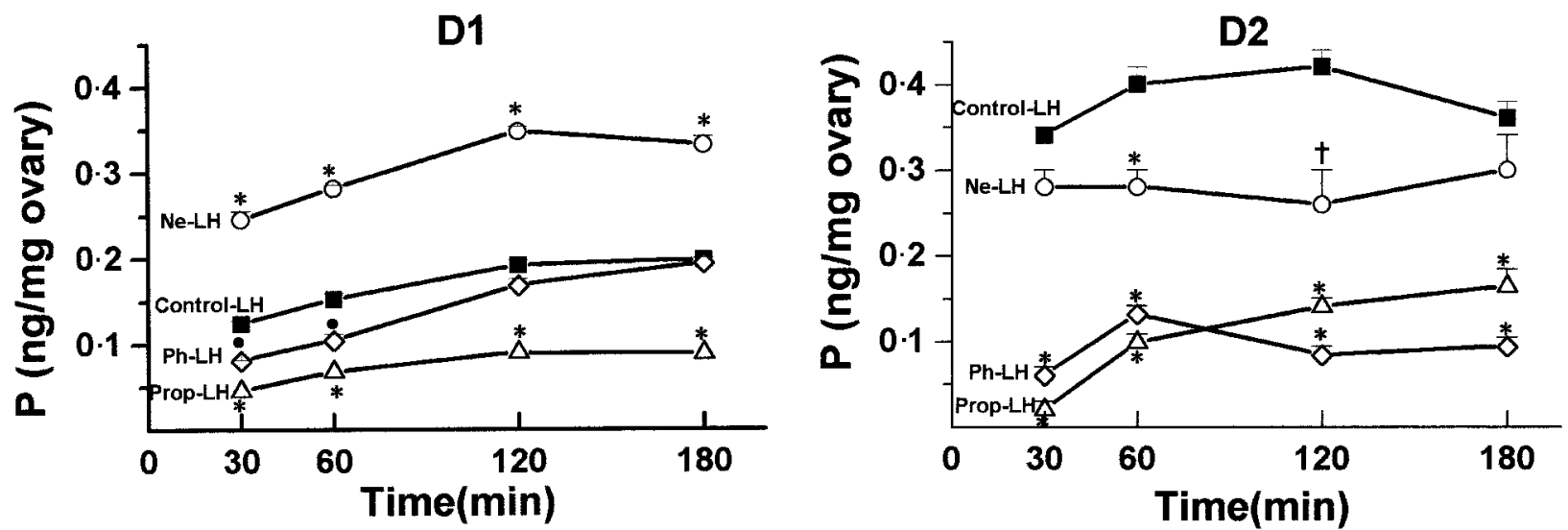

Figure 7 Effect of agonist and antagonist adrenergic agents in ganglion on release of progesterone (P) by the ovary in a coeliac ganglion-SON-ovary system obtained from rats in D1 and D2 with $\mathrm{LH}(50 \mathrm{ng} / \mathrm{ml})$ in the ovarian compartment. The systems were incubated in the presence or absence of agonist and antagonist adrenergic agents at $10^{-6} \mathrm{M}$ in Krebs-Ringer plus ascorbic acid solution at $37{ }^{\circ} \mathrm{C}$ in an atmosphere of $95 \% \mathrm{O}_{2}-5 \% \mathrm{CO}_{2}$ for $180 \mathrm{~min}$. Values are the means \pm S.E.M. from six to eight animals per experimental group. Ne, noradrenaline; Ph, phentolamine; Prop, propranolol. ${ }^{*} P<0 \cdot 001,+P<0 \cdot 01, \bullet P<0 \cdot 05$ compared with the respective control groups (Student's $t$ test). 
transmitter to the ganglion compartment. The effect is verified, also with the addition of LH in the ovary, in this system as well as in the CNS.

In order to verify if the coeliac ganglion-SON-ovary system responds to non-specific stimulation, a moderate concentration $(56 \mathrm{mM})$ of $\mathrm{KCl}$ was added to the ganglion compartment (Koh \& Hille 1997). As expected, different responses were obtained according to the physiological conditions of each stage.

After establishing the spatial location of the system by means of histological studies, we demonstrated, by means of non-specific stimulations, that the ganglia have their own tone, and that the system was viable. Furthermore, knowing also that, in the superior cervical ganglion as in other sympathetic ganglionic systems, in vitro studies have detected $\alpha$ - and $\beta$-adrenergic receptors (Shivachar \& Eikenburg 1999), we wanted to observe, in our system, whether the occupation of adrenergic receptors by agonists (noradrenaline) and antagonists (phentolamine and propranolol) produced the response of release of ovarian steroids; if so, this would confirm the presence of such receptors (Eccles \& Libet 1961, Christ \& Nishis 1971, Erankö 1978).

When the stimulation was performed with adrenergic agents, the addition of noradrenaline $10^{-6} \mathrm{M}$ to the ganglion compartment during pro-oestrus did not cause significant changes in the release of progesterone from the ovary, except after $60 \mathrm{~min}$ of incubation. At this stage of the cycle, the preovulatory peak of LH takes place and, possibly, in the face of this stimulus, the action of noradrenaline is not as noticeable as it is during pregnancy (unpublished data). In oestrus, a similar response was observed, perhaps because during this stage, after ovulation, the corpus luteum had only just been organised and was therefore unresponsive. The stimulation during D1 showed a remarkable increase in the release of ovarian progesterone at all times studied. This is to say that during this stage the corpora lutea are in full activity, which would be the reason why the adrenergic effect on the secretion of progesterone is greater. In addition, in in vivo studies, a peak in the release of progesterone has been observed during D1 that is probably neural in origin (Kawakami et al. 1972, Weiss et al. 1982, Gerendai et al. 1995). During D2, a very noticeable inversion occurs that is concordant with results that were obtained by CNS stimulation (Kawakami et al. 1981, De Bortoli et al. 1998). It cannot be ignored that during pro-oestrus, oestrus and especially during D1, noradrenaline is being released from the nerve endings, as the response is the same as that obtained when the ovary is stimulated directly with noradrenaline in in vitro systems (Aguado \& Ojeda 1984a). In contrast, during D2, noradrenaline would not be liberated, as the effect is inhibitory and, when the ovary is stimulated with noradrenaline, the release of progesterone generally increases (Aguado \& Ojeda 1984a). With respect to phentolamine, during pro-oestrus and D1 the release of progesterone is inhibited, whereas in oestrus it is stimulated. During D2, phentolamine does not modifiy basal concentrations of progesterone.

The addition of propranolol to the ganglion compartment during oestrus, D1 and D2 stimulates the liberation of progesterone, achieving its maximum effect in D2, having been inactive in pro-oestrus.

With respect to similar changes in progesterone output caused by both phentolamine and propranolol, we have not been able, using our experimental scheme, to confirm that the observed effect is, or is not, specific. It can only be noted that this effect is observed in oestrus, when phentolamine and propranolol produce significant changes - in this case stimulatory - in the liberation of progesterone, although of different magnitude. This could suggest the presence of $\alpha$ - and $\beta$-adrenergic receptors in the ganglionic neurones, and possibly different response of these receptors, depending on the antagonists used and the ganglionic neurones in which the receptors are located. Alternatively, in oestrus the corpus luteum is being organised, in contrast with di-oestrous, when different responses are observed in the presence of antagonists in the ganglion. We are, however, able to affirm that the presence of these agents in the coeliac ganglion modifies the release of progesterone according to the stage of the oestrous cycle.

In order to compare the combined neural and endocrine effects on the ovarian release of progesterone, the experiment was carried out during stages D1 and D2, when the corpora lutea are at their peak of activity. When LH was added to the ovarian compartment, concentrations of progesterone increased significantly with respect to their basal values, the greatest values being obtained in D2 (Richardson 1986). In contrast, when LH was added to the ovarian compartment and the adrenergic agonist and antagonists were added to the ganglion compartment, the most noteworthy aspect of the experiment was that, during D1, the effect of noradrenaline increased the release of progesterone even more, surpassing the increase obtained in the presence of LH alone in the ovary. With regard to phentolamine and propranolol, the effect of noradrenaline was reversed, the $\beta$ antagonist having a more significant effect.

During D2, noradrenaline, phentolamine and propranolol produced a marked inhibition of the effect of $\mathrm{LH}$. These results prove the functionality of the system, as the hormonal action produced by the gonadotrophin is modified by the neural action, facilitating the decrease in progesterone concentration that is necessary to start a new cycle.

The fact that, at all stages, noradrenaline almost always increased the release of progesterone, only diminishing in D2, may be interpreted as an indication that ganglionic stimulation causes the discharge of a substance that stimulates the release of progesterone in the ovary during 
pro-oestrus, oestrus and $\mathrm{D} 1$; the possibility that the substance is noradrenaline cannot be disregarded (Dissen et al. 1993, Aguado \& Ojeda 1984a,b). Meanwhile during D2, the observed inhibitory effect is not consistent with the effect of the adrenergic agonist on the ovary. Whenever adrenergic receptors are stimulated in ovarian incubations, or in culture of granulosa cells, liberation of progesterone increases, and never diminishes (Hernandez et al. 1988). In view of the preceding observations, we cannot interpret in the same way the decrease in the values of ovarian progesterone with respect to its controls on D2 when noradrenaline is added to the ganglionic compartment. Neither can we explain the decrease in progesterone when it is phentolamine that is added to the ganglionic compartment in pro-oestrus and on D1. These results lead us to believe that it could be another neurotransmitter that is finally released in the ovary. We could also postulate that other synaptic circuits are established in the ganglion - that is, it is not only noradrenaline that is released, but also other neurotransmitters, such as neuropeptide Y or VIP, which could themselves regulate the release of noradrenaline (Ojeda et al. 1989, Ferruz et al. 1992). This is a possibility that remains to be investigated.

Of the known peptidergic neurotransmitters located in the ganglion that are transported to the ovary through the SON, none has an inhibitory effect on the release of progesterone. In general, their effect is stimulatory, as in the case of VIP (Ahmed et al. 1986, Dissen et al. 1993, Kaleczyc et al. 1995). On the basis of what has been stated, we can only speculate about the possible release of other substances with inhibitory effect, in the ovary during D2, in response to stimulation of the ganglion. One such substance, $\mathrm{GnRH}$, in addition to its classical releasing action at the pituitary level, acts on multiple extrapituitary sites to regulate various reproductive functions. This peptide has shown inhibitory effects on the release of progesterone in luteal cells, in both in vitro and in vivo conditions (Clayton et al. 1979, Jones \& Hsueh 1980, 1981, 1982a,b, Massicote et al. 1981). In the rat ovary, specific high-affinity $\mathrm{GnRH}$ receptors in granulosa and theca cells and a GnRH-like substance have been identified, although the presence of an ovarian GnRH-like substance still remains difficult to confirm (Birnbaumer et al. 1985, Séguin et al. 1982). In addition to their action at the gonadal level, GnRH or GnRH-like peptides may have important roles as neurotransmitters in the CNS (Hsueh et al. 1983). Thus GnRH and GnRHlike peptides may have important paracrine and neurotransmitter roles in the regulation of various reproductive functions in extrapituitary sites (Berhman et al. 1980, Smith-White \& Ojeda 1983). These substances have been found in sympathetic ganglia, for which reason we suppose that, from here, they could reach the ovary via the SON, or that their presence in the ganglia could modulate the release of noradrenaline in the ovary (Jan et al. 1979,
1980, Jan \& Jan 1982, Sejnowski 1982, Reprintseva et al. 1986).

Other factors that might be exerting an influence during D2 could include GABA (Erdö et al. 1985, Castelli et al. 1999), as there is some evidence to indicate that GABA can increase ovarian blood flow, and increase the secretion of oestradiol while decreasing the secretion of progesterone (Erdö et al. 1985). The epidermal growth factors have an inhibitory action on ovarian and testicular steroidogenesis (Hsueh et al. 1981); however, the physiological significance of these peptides is not yet known.

With this experimental design we cannot know, for the time being, which is the neurotransmitter that is finally released in the ovary. What we are sure of is that the coeliac ganglion modifies its activity when is stimulated by adrenergic agonists or antagonists, and that these influences arrive at the ovary through the SON and modify the release of progesterone. In conclusion, by utilising an experimental design that allows us to make observations independent of the humoral factors that affect the ovary, we have been able to confirm that the coeliac ganglion has a direct neural effect on activation of the corpus luteum, and thus on the release of progesterone. The experimental scheme is, in our opinion, a valuable tool for the study of the participation of peripheral neural influences in ovarian physiology.

\section{Acknowledgements}

This work was supported by Grant 3711/92 from CONICET (Consejo Nacional de Investigaciones Cientí ficas y Técnicas, Argentina) and by Grant 9302 from Universidad Nacional de San Luis, Argentina. The authors are very grateful to $\operatorname{Dr} R$ P Deis who provided the progesterone antiserum and to the Cathedra of Histology. Also to Lic Gustavo Pinamonti.

\section{References}

Advis JP \& Ojeda SR 1978 Hyperprolactinemia-induced precocious puberty in the female rat: ovarian site of action. Endocrinology 103 924-935.

Advis JP, Andrews WW \& Ojeda SR 1979 Changes in ovarian steroidal and prostaglandin $\mathrm{E}$ responsiveness to gonadotropins during the onset of puberty in the female rat. Endocrinology 104 653-658.

Aguado LI \& Ojeda SR 1984a Ovarian adrenergic nerves play a role in maintaining preovulatory steroid secretion. Endocrinology 114 1944-1946.

Aguado LI \& Ojeda SR $1984 b$ Prepubertal ovarian function is finely regulated by direct adrenergic influences: role of noradrenergic innervation. Endocrinology 114 1845-1853.

Aguado LI \& Ojeda SR 1986 The prepubertal rat ovary: hormonal modulation of the beta adrenergic receptors and progesterone response to adrenergic estimulation. Biology of Reproduction 34 $45-50$. 
Aguado LI, Petrovic SL \& Ojeda SR 1982 Ovarian adrenergic receptors during the onset of puberty: characterization, distribution and coupling to steroidogenic responses. Endocrinology $\mathbf{1 1 0}$ $1124-1132$

Ahmed CE, Dees WL \& Ojeda SR 1986 The inmature rat ovary is innervated by vasoactive intestinal peptide (VIP)-containing fibers and responds to VIP with steroid secretion. Endocrinology 118 1682-1689.

Baljet B \& Drukker J 1980 The extrinsic innervation of pelvic organ in the female rat. Acta Anatomica 107 241-267.

Behrman HR, Preston SL \& Hall AK 1980 Cellular mechanism of the antigonadotropic action of LHRH in the corpus luteum. Endocrinology 107 656-664.

Birnbaumer L, Shababi N, Rivier J \& Vale W 1985 Evidence for a physiological role of gonadotropin releasing hormone $(\mathrm{GnRH})$ or GnRH-like material in the ovary. Endocrinology 116 1367-1270.

Burden HW 1978 Experimental studies on the acetylcholinesterase positive nerves in the ovary of the rat. Anatomical Record 190 233-242.

Burden HW 1985 The adrenergic innervation of mammalian ovaries. In Catecholamines as Hormone Regulators, vol 18, edn 165, pp 261-265. Eds N Ben-Jonathan, JN Bahr \& RI Weisner. New York: Raven Press.

Burden HW \& Lawrence JE 1977 The effect of denervation on compensatory ovarian hypertrophy. Neuroendocrinology 23 368-375.

Burden HW, Leonard M, Smith CP \& Lawrence IE Jr 1982 The sensory innervation of the ovary: a horseradish peroxidase study in the rat. Anatomical Record 207 623-627.

Bussmann LE \& Deis RP 1979 Studies concerning the hormonal induction of lactogenesis by prostaglandin $\mathrm{F}_{2} \alpha$ in pregnant rats. Journal of Steroid Biochemistry and Molecular Biology 11 1485-1489.

Butcher RL 1977 Changes in gonadotropins and steroids associated with unilateral ovariectomy of the rat. Endocrinology 101 830-839.

Castelli MP, Ingianni A, Stefanini E \& Gessa GL 1999 Distribution of GABA (B) receptor mRNAs in the rat brain and peripheral organs. Life Sciences 6415 1321-1328.

Chávez R \& Domínguez R 1994 Participation of the superior ovarian nerve in the regulation of compensatory ovarian hypertrophy: the effects of its section performed on each day of the oestrous cycle. Journal of Endocrinology 140 197-201.

Chávez R, Carrizosa L \& Domínguez R 1991 Effects of superior ovarian nerve on spontaneous and induced ovulation in adult rats. Medical Science Research 19 41-48.

Chiapas SA, Fink G \& Sherwood MM 1977 Immunoreactive luteinizing hormone releasing factor (LHRF) in pituitary stalk plasma from female rats: effect of stimulating diencephalon, hippocampus and amygdala. Journal of Physiology 267 625-640.

Christ DD \& Nishis 1971 Site of adrenaline blockade in the superior cervical ganglion of the rabbit. Journal of Physiology 213 107-117.

Clayton RN, Harwood JP \& Catt KJ 1979 Gonadotropin releasing hormone analogue binds to luteal cells and inhibits progesterone production. Nature $28290-92$.

Condon WA \& Black DL 1976 Catecholamine induced stimulation of progesterone by the bovine corpus luteum in vitro. Biology of Reproduction 15 573-578.

De Bortoli MA, Garraza MH \& Aguado LI 1998 Adrenergic intracerebroventricular stimulation affects progesterone concentration in the ovarian vein of the rat: participation of the superior ovarian nerve. Journal of Endocrinology 159 61-68.

Dissen GA, Les Dees WL \& Ojeda SR 1993 Neural and neurotrophic control of ovarian development. In The Ovary, pp 1-18. Eds EY Adashi \& CK Leung. New York: Raven Press.

Donoso AO 1988 Luteinizing hormone release induced by noradrenaline after administration of drugs that increase hypothalamic GABA levels. Acta Physiologica Pharmacologica et Therapeutica Latinoamerica 38 11-18.
Eccles RM \& Libet B 1961 Origin and blockade of the synaptic responses of curarized sympathetic ganglia. Journal of Physiology 157 484-563.

Erankö O 1978 Small intensily fluorescent (SIF) cells and nervous transmission in sympathetic ganglia. Annual Review of Pharmacology and Toxicology 18 417-430.

Erdö SL, Varga B \& Horvath E 1985 Effect of local GABA administration on rat ovarian blood flow and on progesterone and estradiol secretion. European Journal of Pharmacology 111 397-404.

Erickson GF, Magoffin DA, Dyer CA \& Hofeditz C 1985 The ovarian androgen producing cells: a review of structure/function relationships. Endocrine Reviews 6 371-399.

Ferruz J, Ahmed CE, Ojeda SR \& Lara HE 1992 Norepinephrine release in the immature ovary is regulated by autoreceptors and neuropeptide-Y. Endocrinology 130 1345-1351.

Gerendai I, Marchetti B, Maugeri S, Amico Roxas M \& Scapagnini V 1978 Prevention of compensatory ovarian hypertrophy by local treatment of the ovary with 6-OHDA. Neuroendocrinology 27 272-279.

Gerendai I, Csaba Zs, Voko Z \& Csernus V 1995 Involvement of a direct neural mechanism in the control of gonadal functions. Journal of Steroid Biochemistry and Molecular Biology 53 299-305.

Hernandez ER, Jimenez JL, Payne DW \& Adashi EY 1988 Adrenergic regulation of ovarian androgen biosynthesis is mediated via $\beta_{2}$ adrenergic theca interstitial cell recognition sites. Endocrinology 122 1592-1601.

Hsueh AJW \& Erickson GF 1979 Extrapituitary action of gonadotropin releasing hormone: direct inhibition of ovarian steroidogenesis. Science 204 845-855.

Hsueh AJW \& Jones PBC 1981 Extrapituitary actions of gonadotropin-releasing hormone. Endocrine Reviews 2 437-461.

Hsueh AJW, Welsh TH Jr \& Jones PBC 1981 Inhibition of ovarian and testicular steroidogenesis by epidermal growth factor. Endocrinology 108 2002-2004.

Hsueh AJW, Adashi EY, Tucker E \& Volkgy Ling N 1983 Relative potencies of gonadotropin releasing hormone agonist and antagonists on ovarian and pituitary functions. Endocrinology 112 689-672.

Hsueh AJW, Adashi EY, Jones PBC \& Welsh TH 1984 Hormonal regulation of the differentiation of cultured ovarian granulosa cells. Endocrine Reviews 5 76-127.

Jan LY \& Jan YN 1982 Peptidergic transmission in sympathetic ganglia of the frog. Journal of Physiology 7 219-246.

Jan YH, Jan LY \& Kuffler SW 1979 A peptide as a possible transmitter in sympathetic ganglia of the frog. PNAS 3 1501-1505.

Jan LY, Jan YN \& Brownfiel MS 1980 Peptigergic transmitter in synaptic boutone of sympathetic ganglia. Nature 288 380-382.

Jones PB \& Hsueh AJ 1980 Direct inhibitory effect of gonadotropin-releasing hormone upon luteal luteinizing hormone receptor and steroidogenesis in hypophysectomized rats. Endocrinology 107 1930-1936.

Jones PB \& Hsueh AJ 1981 Direct stimulation of ovarian progesterone-metabolizing enzyme by gonadotropin-releasing hormone in cultured granulosa cells. Journal of Biology and Chemistry $2561248-1254$.

Jones PB \& Hsueh AJ 1982a Pregnenolone biosynthesis by cultured granulosa cells: modulation by follicle-stimulating hormone and gonadotropin releasing hormone. Endocrinology 111 713-721.

Jones PB \& Hsueh AJ $1982 b$ Regulation of ovarian $3 \beta$-hydroxysteroid dehydrogenase activity by gonadotropin-releasing hormone and follicle-stimulating hormone in cultured rat granulosa cells. Endocrinology 110 1663-1671.

Jordan AW 1981 Changes in ovarian beta adrenergic receptors during the estrus cycle of the rat. Biology of Reproduction 24 245-248.

Kaleczyc J, Majewski M, Kakomy M \& Sienkiewics V 1995 Occurrence and coexistence of some neuropeptides in nerve fibers supplying the bovine ovary and its extrinsic blood vessels. Folia Histochemica et Cytobiologica 33 163-169. 
Kawakami M, Seto K, Terasawa E \& Kimura F 1972 Role of the limbic-hypothalamic system in relation to ovulation and ovarian steroidogenesis. Medical Journal of Osaka University 23 57-75.

Kawakami M, Kubo K, Uemura T \& Nagase M 1979 Evidence for the existence of extra-hypophyseal neural mechanisms controlling ovarian steroid secretion. Journal of Steroid Biochemistry 11 1001-1005.

Kawakami M, Kubo K, Uemura T, Nagase M \& Hayashi R 1981 Involvement of ovarian innervation in steroid secretion. Endocrinology 109 136-145.

Klein CM \& Burden HW 1988a Anatomical localization of afferent and postganglionic sympathetic neurons innervating the rat ovary. Neuroscience Letters 85 217-222.

Klein CM \& Burden HW 1988b Substance P and vasoactive intestinal polypeptide (VIP) immunoreactive nerve fibers in relation to ovarian postganglionic perikarya in para- and prevertebral ganglia: evidence from combined retrograde tracing and immunocytochemistry. Cell and Tissue Research 252 403-410.

Koh DS \& Hille B 1997 Modulation by neurotransmitters of catecholamine secretion from sympathetic ganglion neurons detected by amperometry. PNAS 94 1506-1511.

Lara HE, Mc Donald JK \& Ojeda SR 1990a Involvement of nerve growth factor in female sexual development. Endocrinology 126 364-375.

Lara HE, McDonald JK, Ahmed CE \& Ojeda SR $1990 b$ Guanethidine-mediated destruction of ovarian sympathetic nerves disrupts ovarian development and function in rats. Endocrinology 127 2199-2209.

Lawrence IE Jr \& Burden HW 1980 The origin of the extrinsic adrenergic innervation to the ovary. Anatomical Record 196 51-59.

Marchetti B, Cioni M, Badr M, Folléa N \& Pelletier G 1987 Ovarian adrenergic nerves directly participate in the control of LHRH and beta adrenergic receptors during puberty: biochemical and autoradiographic study. Endocrinology 121 219-226.

Massicote J, Borgus JP, Lachance R \& Labrie F 1981 Inhibition of HCG-induced cyclic AMP accumulation and steroidogenesis in rat luteal cells by an LHRH agonist. Journal of Steriod Biochemistry 14 239-242.

Messenger JP, Furness JB \& Trudruing P 1994 Locations of postganglionic nerve cells whose axons nerves originate from prevertebral ganglia. Archives of Histology and Cytology 57 405-413.

Norjavaara E, Rosberg S, Gafvels M, Boberg BM \& Selstam G 1989 Beta adrenergic receptor concentration and subtype in the corpous luteum of the adult pseudopregnant rat. Journal of Reproduction and Fertility 86 567-575.

Ojeda SR \& Aguado LI 1985 Adrenergic control of the prepubertal ovary: involvement of local innervation and circulating catecholamines. In Catecholamines as Hormone Regulators, pp 293-310. Eds N Ben-Jonathan, JM Bahr \& RI Weiner. New York: Raven Press.

Ojeda SR \& Lara HE 1989 Role of the sympathetic nervous system in the regulation of the ovarian function. In The Menstrual Cycle and Its Disorders, pp 26-35. Eds KM Pirke, W Wuttke \& U Schweiger. Berlin: Springer-Verlag.

Ojeda SR, Lara H \& Ahmed CE 1989 Potential relevance of vasoactive intestinal peptide to ovarian physiology. Seminars in Reproduction and Endocrinology 7 52-755.
Pieper DR, Richards J \& Marshall J 1981 Ovarian gonadotropinreleasing hormone $(\mathrm{GnRH})$ receptors: characterization, distribution and induction by GnRH. Endocrinology 108 1148-1155.

Reprintseva VM, Martinovich VP, Polikarpova VI \& Slobodchikova LK 1986 Peptide modulation of spontaneous and evoked catecholamine release in the mesenteric ganglion of the dog. Fiziologicheskii Zhurnal SSSR Imeni I.M. Sechenova 8 1084-1090.

Richardson MC 1986 Hormonal control of ovarian luteal cells. Oxford Reviews of Reproductive Biology 8 321-378.

Saito H, Kaba H, Sato T, Kondo M, Takeshima Y, Edashige N, Seto K \& Kawakami M 1990 Influence of electrical stimulation of the hypothalamus on ovarian steroidogenesis in hypophysectomized and adrenalectomized rats. Experimental and Clinical Endocrinology 2 259-261.

Sarper CB, Loewy AD, Swanson LW \& Cowan WM 1976 Direct hypothalamo-autonomic connections. Brain Research 117 305-316.

Séguin C, Pelletier G, Dubé D \& Labrié F 1982 Distribution of luteinizing hormone-releasing hormone receptors in the rat ovary. Regulatory Peptides 4 183-188.

Sejnowski T 1982 Peptidergic synaptic transmission in sympathetic ganglia. Federation Proceedings 13 2923-2928.

Selstam G, Rosberg S, Liljekvist J, Gronquist L, Perklev T \& Ahrén K 1976 Differences in action of LH and FSH on the formation of cyclic AMP in the prepubertal rat ovary. Acta Endocrinologica $\mathbf{8 1}$ 150-164.

Seto K, Saito H, Kaba H, Honmura A, Li CS, Nikagawa M, Ikeda H \& Kawakami M 1988 Influence of electrical stimulation of the limbic structure on ovarian steroidogenesis in hypophysectomized and adrenalectomized rats. Experimental and Clinical Endocrinology 2 235-237.

Sheela Rani CS, Ekholm C, Billig H, Magnusson C \& Hillensjö T 1983 Biphasic effect of gonadotropin releasing hormone on progestin secretion by rat granulosa cells. Biology of Reproduction $\mathbf{2 8}$ 591-597.

Shivachar AC \& Eikenburg DC 1999 Differential effects of epinephrine and norepinephrine on cAMP response on protein expression in cultured sympathetic neurons. Journal of Pharmacology and Experimental Therapeutics 1 258-264.

Snedecor GW \& Cochran WG 1976 Statistical Methods. Ames, Iowa: The Iowa State University Press.

Smith-White S \& Ojeda SR 1983 Peripubertal decline in ovarian LHRH receptor content: characterization and distribution. Neuroendocrinology 36 449-459.

Telleria CM, Carrizo DG \& Deis RP 1994 Levonorgestrel inhibits luteinizing hormone stimulated progesterone production in rat luteal cells. Journal of Steroid Biochemistry and Molecular Biology 50 161-166.

Weiss GK, Dail WG \& Ratner A 1982 Evidence for direct neural control of ovarian steroidogenesis in rats. Journal of Reproduction and Fertility 65 507-515.

Received 29 November 1999

Revised manuscript received 17 March 2000

Accepted 28 March 2000 